\title{
LETTERS
}

\section{Is it time for \#UsToo in the medical profession?}

We thank Drs. Holroyd-Leduc and Straus for their thoughtful response ${ }^{1}$ to the letter from Dr. Satenstein. ${ }^{2}$ We agree that any form of discrimination is unacceptable, including the lower limits reported in the literature, and mechanisms to mitigate discrimination are required. We draw further attention to another gap in the current literature: investigating the numerous social divisions (e.g., gender identity, sexual identity, sexual orientation, race, ability, class and social norms) that lead to discrimination. Typically, discrimination is classified under the terms of distinctions of gender and race, yet everyday experiences are often more complicated.

For example, gender and sex are not natural binaries. Certain individuals transcend biological phenotypic categories; ${ }^{3}$ gender may be contextualized, socialized and dynamic. Just as the demographics of physicians are shifting to include nearly a majority of women, so is the spectrum of gender identities and sexual orientations. Despite this, little is known about the experiences of "nonconforming" physicians in contemporary practice.

In sociology, privilege encompasses the real or perceived advantages that are available to a particular individual or group. ${ }^{4}$ The opposite of privilege is disability, and the individual deprivation of power and authority by societal structures and policies create disempowerment. ${ }^{5}$ Disempowerment to connote disability results from complex sociostructural factors. ${ }^{5}$ Furthermore, privilege and disempowerment exist along a dynamic continuum, with each of us situated at different places along the spectrum at any given time.

The privilege-disempowerment spectrum can best be explained through example. The surgical mask can be used as a metaphor, as people wearing the mask look similar irrespective of social divisions. Although tempting, diversity is not always simple and easy to define; society must remain cognizant of the historical and sociopolitical differences of each of the social divisions and not undervalue or underappreciate any with its inherent hardships that cannot be fully represented by an allencompassing term such as diversity.

When considering inclusion and diversity policies, we must consider that privilege and disempowerment can be in a constant state of flux with potentially opposing and, at times congruent, factors (for example, a male physician with a nonconforming sexual identity; a female physician who belongs to a racial minority group; a male physician who is a recent immigrant). Although we are concurrently situated within the culture of medicine, we need to be conscious not to perpetuate heteronormative and heterosexual qualities, and maintain open perspectives and awareness about ingrained biases that prevent less-empowered individuals from achieving their potential in medicine. ${ }^{6}$

The barriers faced by those who are not naturally privileged or enabled silence diverse perspectives and perpetuate cultural norms of power and influence. The dominant voice is heard, further silencing those without privilege by their absence.

Removing the surgical mask of conformity allows others to be fully seen and participate in their cultural environment, avoiding segregation and isolation. Perhaps a more nuanced \#UsToo movement is required to further dissect all social divisions and examine their effect on culture in medicine.

\section{Gianni R. Lorello MD MSc (Med Ed)}

Staff anesthesiologist, Toronto Western Hospital, University Health Network; assistant professor, Department of Anesthesia, University of Toronto; cross-appointed researcher, The Wilson Centre, Toronto, Ont.

\section{Alana M. Flexman MD}

Staff anesthesiologist, Vancouver General Hospital; clinical associate professor, Department of Anesthesiology, Pharmacology \& Therapeutics, Faculty of Medicine, University of British Columbia, Vancouver, BC

Cite as: CMAJ 2019 April 29;191:E480. doi: $10.1503 / \mathrm{cmaj} .71814$

\section{References}

1. Holroyd-Leduc JM, Straus SE. The authors respond to "Tread carefully with \#MeToo in the medical profession.” CMAJ 2018;190:E1424.

2. Satenstein G. Tread carefully with \#MeToo in the medical profession. CMAJ 2018:190:E1423.

3. Butler J. Gender trouble: feminism and the subversion of identity. 1st ed. New York, London (UK): Routledge; 2011.

4. Cheng W. Geographies of Privilege. France Winddance Twine and Bradley Gardener [book review]. AAG Rev Books 2013;1:172-4.

5. Moonie N. Health \& social care: as level as Edexcel. Oxford (UK): Heinemann; 2005.

6. Rich A. Blood, bread, and poetry: selected prose 1979-1985. New York: W. W. Norton \& Company; 1994.

Competing interests: None declared. 